\title{
In Vino Veritas? Blockchain Preliminary Effects on Italian Wine SMEs
}

\author{
Roberta Cuel and Gabriella Maria Cangelosi
}

\begin{abstract}
Transparency and traceability in the food industry have become two central themes for both consumers and companies. On the one hand, consumer awareness increases with more available in depth information, whilst food manufacturers try to mitigate food safety risks, reduce coordination costs and fraud by improving their presence on the market. In this scenario, innovative technologies and blockchain may have a major impact. The authors investigate the adoption of blockchain in the Italian wine industry and, in particular, the effects of blockchain on the complex inter-organizational supply chain systems SMEs are engaged in. A qualitative approach was chosen to preliminary analyse the motivations driving small Italian wineries to adopt blockchain technologies, and the advantages or drawbacks managers identified during pilot experiments.
\end{abstract}

Keywords Blockchain - Supply chain • Traceability • Transparency • Certification $\cdot$ Wine industry

\section{Introduction}

In recent years, large organizations such as technology companies and financial giants have invested heavily in blockchain-based technologies to radically transform business applications and get considerable benefits. Blockchain would contribute to the execution of secure business processes and the automation of transactions between companies.

Blockchain technology can also be considered a huge opportunity for small and medium organizations that do not have enough resources to invest in new technologies and are thus often left behind when a technological leap forward occurs.

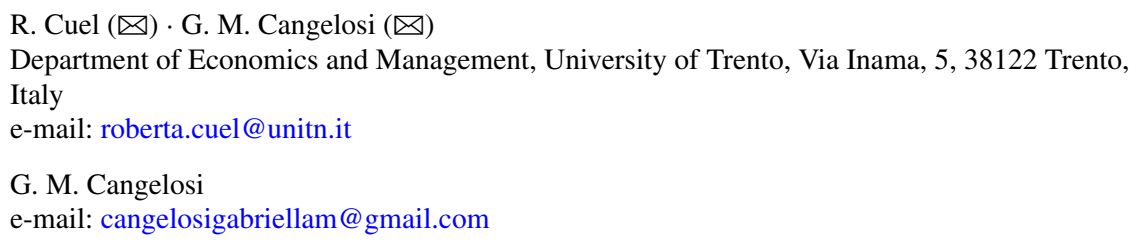


According to some experts, ${ }^{1}$ SMEs can innovate and build an edge with blockchain transformation by using blockchain-based services as well as creating their own apps on top of blockchain such as decentralized apps, or DApps. SMEs can already use different blockchain solutions. For instance, there are marketplaces for renting or selling properties on blockchain-based P2P marketplaces (real estate); managing claims (insurance); dealing with security (IoT), monitoring and tracking freight movement (logistics), and ensuring food safety via IBM's Food Trust Network to link distributors, retailers, producers, and regulators in the food industry [1].

In this paper, the authors focus on SMEs in the Italian wine industry. These companies represent $75-80 \%$ of the Italian production, which has a total turnover of 13 billion Euros, with 310,000 companies involved and 46,000 wine-making companies. $^{2}$ In this scenario, innovative technologies and blockchain may have a major impact that cannot be ignored: at present the impact is most evident on the complex inter-organizational supply chain that SMEs manage and deal with.

A qualitative approach has been chosen in order to preliminary analyse the motivations that drive small Italian wineries to improve their supply chain management by applying blockchain technology [2]. The authors will also focus on the advantages and drawbacks that managers identified during their pilot experiments.

\section{Literature Review}

The blockchain is a Distributed Ledger Technology (DLT), an unalterable database of information related to each transaction carried out and shared between a network of participants [3]. This technology is based on Disintermediation and Decentralization principles, namely that data can be recorded, stored and updated in a distributed manner by all network members [4]. This type of architecture allows actors to maintain and share records in a synchronized manner, ensuring their integrity via validation protocols based on consensus and cryptographic signatures [5]. The governance is based on a widespread and distributed system of mutual trust in which no actor can prevail and where the decision process is built on consensus [6].

\footnotetext{
${ }^{1}$ Blockchain Technology Applications for SMEs [Expert Roundup]—Written by Mindaugas on September 17, 2018 and retrieved from https://blog.invoiceberry.com/2018/09/blockchain-techno logy-applications-sme/.

${ }^{2}$ Federvini-retrieved 10/8/2019 from https://www.federvini.it/studi-e-ricerche-cat/1273-ismea,fotografa-l-italia-del-vino-aumentano-produzione,-valore-ed-export-stabile-la-struttura.
} 


\subsection{Blockchain Based Supply Chain Principles}

Blockchain is an integrative technology conceived with the aim of defragmenting the supply chain through the synchronization of data recorded along the same. It can be considered an integration of the existing information and legacy systems [7].

More specifically, each product is characterized by a processing cycle that involves several actors. Each actor has a unique digital identity (provided by an accreditation service) and the role of recording (tracking) all the key information regarding the development processes of the product (or service) and its status within the network. Each product is assigned to a digital identity using a specific tag (a barcode, RFID or QR Code). This tag is a unique digital cryptographic identifier that connects the physical good to its virtual identity on the network, enabling any actor to retrieve all or any associated information. In order to protect the process from theft and counterfeiting, blockchain involves the creation of a digital token associated with the digital identity when the product/service is made or exchanged between the actors in the supply chain [8]. The final product addressee can, therefore, authenticate the token and follow the history of the article from its beginning [9]. When the product is transferred (or sold) to another actor, both partners must sign a digital contract to authenticate the exchange [10]. Once all the actors have signed the contract, the details of the transaction will be stored. The actors' privacy can be modified according to the preferences of the subject involved: they can choose to remain anonymous, but their identity must be authenticated by the certifiers who guarantee trust [8].

Thus the founding principles of the blockchain technology are:

- Transparency: each participant can view all recorded content at any time. This is why blockchain is considered a reliable tool [11].

- Open source: the system is open to all participants as each registration can be controlled publicly and everyone can freely use the technology to implement any application [12].

- Autonomy: blockchain is a consensus-based system, open to all participating players; it can be modified only once all members have given their approval. Using blockchain, devices are able to interact with others without the involvement of a server [13].

- Immutability: blockchain ensures absolute inalterability and incorruptibility of all information. The only exception is the possession of $51 \%$ of the control of a node [14].

- Anonymity: both the transfer of data and the individual transaction can be anonymous, provided that the blockchain address of the person is known [12].

\subsection{Governance and Blockchain Types}

From a governance point of view, a blockchain can be permissioned or unpermissioned. The permissioned, or authorized, option is the alternative evolution to the 
unauthorized chain (one in which anyone can participate) [15]; examples are Bitcoin and Ethereum [14]. In this case, transparency is only towards authorized participants, which makes it difficult to process data that require some privacy [16]. Two types of subjects can be distinguished:

- Participants who can only use the system and

- Validators who can use the system and hold a copy of the updated ledger. Validators are responsible for the process of distributed consensus [17].

The unpermissioned blockchain does not require owners and allows all participants to own a copy of the updated ledger. In this case, participants may also be validators and are responsible for both the distributed consensus process and the system integrity [18].

Three types of blockchain are classified, namely Public, Consortium and Private, and affect [7]:

- Consensus: the consensus determination is gradual, passing from public, to consortium and finally private. Everyone, in fact, can take part in the public blockchain; in the consortium only a small group of nodes is responsible for the validation of the block; in the private, the chain is entirely controlled by a single organization that can define the final consensus. Moreover, a public blockchain is an example of an unauthorized chain; the other two cases, however, are models of permissioned blockchain [7].

- Transparency: blockchain transactions are entirely visible in the public, but this visibility tends to fade when changing to the consortium and then to the private.

- Immutability: from the point of view of immutability, in the public blockchain transactions are much more complex to manipulate since the number of participants who store the records is greater: the same information in a private or in a consortium system might be easily tampered with.

The main difference between the three blockchain types is that the public is totally decentralized, the consortium is partially decentralized and the private is completely centralized and controlled by a single node.

\section{The Italian Wine Supply Chain with the Use of Blockchain}

Various experiments have been conducted in Italy to introduce blockchain technologies into the agro-food industry and winery sector. Among others, the main goals of these trials are to tackle problems of wine counterfeiting, guarantee the wine origins, certify the product by providing the bottles of wine with a unique identity, track and trace the wine production along the entire supply chain, and to exploit technology innovations when conducting marketing campaigns. 


\subsection{Italian Wine Industry and Innovation}

In a fast changing market, expectations and consumption dynamics change even when the reference industry is typically traditional as is the case of the wine sector. Diverse technologies have been introduced in various stages of the production from the cultivation of grapes (harvesting and destemming) to the vinification process (crushing, primary fermentation, cold stabilization, laboratory tests, blending and fining), bottling, marketing, and to the distribution of the final product. These technologies are being implemented to create added value without diminishing the quality that distinguishes Italian wine around the world. Research in 2017 by the Cisco and Digital Transformation Institute showed that the Italian wine industry's principle investments in innovation took place downstream of the supply chain [19]. At present, $77.3 \%$ of Italian wineries have not invested in ICT technologies nor spent up to $€ 5000$ the last five years. Of the remaining $22.7 \%$ that invested more than $€ 5000$ about half (49\%) is represented by the largest companies. The technologies that are most affecting the wine sector are mainly related to management and business management $(74 \%)$, traceability $(57 \%)$ and the transmission of information in electronic forms $(53 \%)$ [20].

\subsection{Blockchain in the Wine Supply Chain: How Does It Work?}

Ideally, since the wine supply chain commences with the vineyards, the winegrowers should generate the first block in the chain (Fig. 1). This block is checked by the majority number of miners in the system before the next block is created. All the
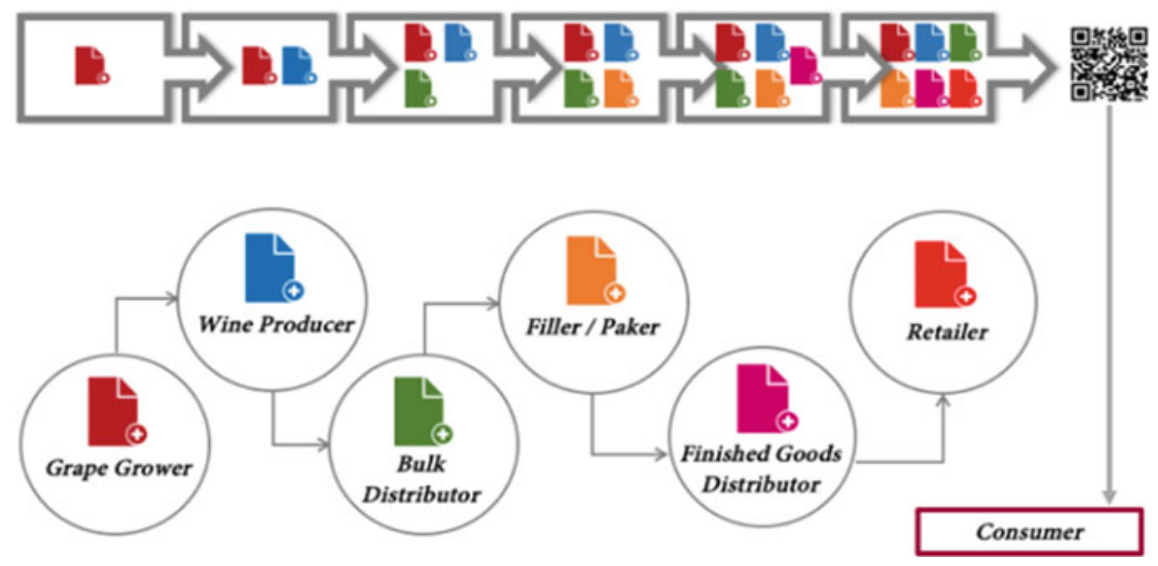

Fig. 1 Blockchain in the wine supply chain (authors' elaboration) 
participants in the chain receive an identification code and a batch number indicating the quantity supplied by the wine producer. In the same way, the producer puts all his recorded information in a further block and shares it with all the other participants. Subsequently, the block is checked again and added to the chain. The procedure is repeated until the final participant. In some cases information shared could be critical and kept private, taking advantage of the cryptography keys that the technology provides [21].

One of the main features of the proposed traceability system is the possibility of tracing the origin of each individual bottle of wine. The consumer can trace the complete flow of data and related information by scanning a tag, e.g. a QR code, placed on the bottle label.

\section{Hypothesis, Research Method and Sample of Analysis}

The purpose of this study is to investigate the impact of blockchain technology in the Italian wine sector. Through ethnographic interviews conducted on a sample of companies, the authors explore both the benefits and limitations perceived by developers and managers in pilot experiments where blockchain technology was adopted to certify, track and trace the agro-food supply chain.

Two hypothesis are analysed:

- H1: blockchain technology allows effective and efficient control of interorganizational business processes and the supply chain flow.

- H2: blockchain technology it is a transparency vehicle, both inside the company and in the relationship between the firm and the final consumer.

An exploratory and comparative survey was carried out by means of semistructured qualitative interviews with eight managers who were involved in the pilot projects. In order to obtain a complete scenario, the authors also interviewed two representatives of companies that develop and resell blockchain technology in the agro-food sector.

The authors adopted the inductive "emergent" method where results derive from the observation, analysis and comparison of empirical evidence, and particular manifestations of the companies' experiences, facts and circumstances in the considered context. A research model inspired by the Grounded Theory was adopted as the main reference in the analysis of the text (coding). Through interviews focused on coding, categories and subcategories were defined, compared during the analysis of the interviews, and grouped into theme sets. The authors developed the latter through a thorough reading of the interviews and examining long pieces of the reported texts. The categories considered most important were used to explain the macro-themes and the sub-themes identified. Using NVivo software, the categories are represented by the nodes and the subcategories by the child nodes.

The sample of analysis contains SMEs operating in the Italian wine industry. The authors contacted all the companies that are presently investing in technology 
Table 1 "Sample respondents" features (personal elaboration)

\begin{tabular}{l|l|l|l}
\hline Respondent & Position & Project & Project owner \\
\hline Respondent 1 & Co-owner & MyStory & DNV GL \\
\hline Respondent 2 & Biologist & $\begin{array}{l}\text { Wine } \\
\text { blockchain EY }\end{array}$ & EY \\
\hline Respondent 3 & $\begin{array}{l}\text { Export } \\
\text { manager }\end{array}$ & $\begin{array}{l}\text { Wine } \\
\text { blockchain EY }\end{array}$ & EY \\
\hline Respondent 4 & Owner & eNology & MIPAAFT \\
\hline Respondent 5 & $\begin{array}{l}\text { Quality } \\
\text { manager }\end{array}$ & MyStory & DNV GL \\
\hline Respondent 6 & $\begin{array}{l}\text { Quality } \\
\text { manager }\end{array}$ & MyStory & DNV GL \\
\hline Respondent 7 & Owner & eNology & MIPAAFT \\
\hline Respondent 8 & Owner & eNology & MIPAAFT \\
\hline
\end{tabular}

and adopting a supply chain system based on blockchain, but only seven answered and were available for further contact and interviews. To obtain complete explorative information, individuals with different organizational roles were interviewed (Table 1). The companies joined three different pilot projects aimed at experimenting with blockchain technology to track, trace and certify products. Three out of the seven companies are part of DNV GL, one of the most important certification authorities in Europe in the agro-food industry. One of the companies has joined the Ernst and Young project in collaboration with the start-up technology developer, EZ lab. Three companies have been involved in the testing program supported by the Italian Ministry of Agriculture and Forestry (MIPAAFT), in collaboration with Almaviva (a developer), SIAN (National Agricultural Information System) and AGEA (Agricultural Supplies Agency).

\section{Result of Analysis}

From an in-depth reading of the interviews, the authors identified 11 categories and 15 sub-categories. The coded nodes emerged from the most recurrent, sometimes implicit, issues discussed during the interviews. Although a detail-oriented analysis was carried out, the degree of abstraction of the conceptualization is quite high. Using NVivo coding, macro-themes were distinguished from sub-themes (Table 2). The purpose of the aforementioned subdivision between nodes and sub-nodes is to clarify the multiple facets of each of the 12 themes that emerged. In the following sub-paragraphs, the authors comment on each of them, once grouped by identifying the boundary objects between each of them. 
Table 2 Groups of macro-themes and sub-themes (authors' elaboration)

\begin{tabular}{l|l|l}
\hline Groups & Macro-themes & Sub-themes \\
\hline \multirow{2}{*}{ Group 1 } & 1. Certification & $\begin{array}{l}\text { Quality and sustainability; role of the certification body; role of } \\
\text { the blockchain }\end{array}$ \\
\cline { 2 - 3 } & 2. Transparency & Company-consumer relationship \\
\cline { 2 - 3 } & 3. Traceability & Tracing \\
\hline \multirow{2}{*}{ Group 2 } & 4. Communication & Reputation and image \\
\cline { 2 - 3 } & 5. Strategy & \\
\cline { 2 - 3 } & 6. Processes & Supply chain management \\
\hline Group 3 & 7. Collaboration & Complexity \\
\cline { 2 - 3 } & 8. Safety & Trust; inalterability of the data; privacy; regulation \\
\cline { 2 - 3 } & $\begin{array}{l}\text { 9. Territorial } \\
\text { identity }\end{array}$ & \\
\hline Group 4 & 10. Training & Skills; required roles \\
\cline { 2 - 3 } & 11. Dissemination & \\
\hline
\end{tabular}

\subsection{Group 1: Certification, Transparency and Traceability}

All the respondents consider essential the registration in the blockchain of only the information validated a priori by a certification body. In their opinion, being certified by a third body protects the company from its own responsibility but also protects the consumers.

[...] there is an impartial entity that testifies, guaranteeing that this data is true. I pay the certification body to attest that my work meets the requirements of the standard for which I certify my work. [...] The certification body acts as my guarantor by promoting its brand. [Respondent 5].

This consideration calls into question the usefulness of blockchain technology as an autonomous and independent certification system in the agro-food supply chain. It is not clear to the interviewees what differences there are between the operation needed for traditional certification and that of the blockchain. In other words, the procedure for blockchain seems almost repetitive.

All this, however, is already done by certification bodies that check me step by step in this process $[\ldots]$ So it makes no sense to do it twice also because [...] with the blockchain no one is verifying your data; you are the one who in good faith decides to load it into blockchain and then make it unchangeable. [Respondent 1].

With regard to the issue of transparency, two very interesting aspects emerge from the analysis: the desire to be completely frank and transparent with the consumers and win him over or allow the consumer himself to easily understand the product he/she is buying. In the first case, the blockchain is seen as a tool that can be used to enhance the reputable image of the company. In the second, the reflection shifts to the opportunity to offer consumers more information and a more interactive, engaging 
and aware approach in evaluating the products he/she is purchasing. One of the respondents defined this as "consumer empowerment".

The topic is, as always, consumer empowerment. Do consumers freely choose the product? Are their choices dominated by brands, distribution channels or industries? The blockchain gives power to the consumer and we like it because consumers are able to acquire more information than other certification mechanisms. These latter are usually find on the product labels, but it is not clear what value they give the consumers. [Respondent 3].

As regard tracing, certifying the supply chain also means offering the consumer the instruments to go back over the supply chain, even to the raw material. Equal importance is given to both the traceability and the product certification profiles. This is because if there were a problem with the quality/composition/state of the product, it would be crucial to trace it back to its origin. For example, with blockchain, it would be easier to identify a damaged batch number, thus avoiding an enormous waste of resources on the part of the company.

[...] the person knows where that bottle comes from, otherwise he would only know that it has been certified, namely that it satisfies the certification requirements. [Respondent 7].

\subsection{Group 2: Communication, Strategy, and Processes}

The internal motivations that drove managers to join the pilot experiments were codified into the following categories: "Communication", "Strategy", and "Processes".

As for the first node, the authors returned to discuss the relationship between company and consumer, recalling the previous "Transparency" category. The transparency principle represents the first boundary object between the first two groups of nodes. However, due to the short term of involvement in the pilot project, the companies did not fully discern the effects of the blockchain on consumer engagements. In fact, while the information about values, history and certifications transmitted is considered a guarantee for the consumer, not all have a real usefulness.

The interviewees declared that they would like to use blockchain to improve their company's reputation or visibility on the market, or to access new markets. Visibility in the wine company arena is guaranteed by a good reputation on the market, but also by knowing how to be ahead of competitors. In particular, a higher visibility is required in new and foreign markets, where consumers, unlike the Italians, conceive wine as a luxury products and are willing to pay more. In this more demanding market, a more attentive approach to innovative technology might provide some advantages.

[...]in my opinion it is first of all something that guarantees the consumer something extra and it can also be used from the marketing point of view ... so the origin of the vineyard, the production and all these things are data that for the consumer become a sort of warranty. [Respondent 7].

From the point of view of supply chain management, respondents stressed the fact that the control procedures have remained unchanged, without any need for reorganization. 


\begin{abstract}
We already have the issue of supply chain control with or without blockchain. The agriculture sector is one of the most advanced and experimental. We check all our batches of grapes, wine, and what ends up in every single bottle. These data are on paper. [...] 30 years ago we already had and published this information. [Respondent 4].
\end{abstract}

\title{
5.3 Group 3: Collaboration, Safety, and Territorial Identity
}

One of the results that pilot companies verified was that involved actors understood the importance of the documentation provided. The authors did not discover any internal resistance or hostility: what was reported was good team spirit and enthusiasm for the experimentation. The link between the second and third group of nodes is therefore the "collaboration" between the players operating in the supply chain: better supply chain management depends on the maximum cooperation between the parties involved in every stage of the production chain. However, the extra work required to retrieve precise information about a very long term process was found to be the factor of greatest hostility.

[...]Perhaps it becomes more complicated for those who have lots of actors in the supply chain and therefore when farmers, producers, transformers, bottlers and the distribution crews have to coordinate/cooperate [...]. [Respondent 8].

As regards safety, especially on the non-modifiability of the data, the debate opens about the truthfulness of the recorded data and returns, once again, to the discussion on the central role played by the certification body. When there is no certification body mediation (the self-certification case) the problem exists.

The blockchain guarantees the immutability of information, but not its truthfulness. Truthfulness lies in the common sense of the people who upload and provide real data because in this way they open themselves up. [Respondent 1].

Furthermore, the trust question relies not only on the good faith of those who are uploading data to blockchain, but also on the guarantee of the reliability of a system that, according to most experts, should protect against fraud and counterfeit products. Not all respondents saw the absence of regulation and laws as a limit possibly because they believe that the aspects of traceability and the information that the consumer can actually read from the QR Code scan have a greater weight.

$[\ldots]$ This thing goes beyond any type of regulatory system. [...] with the blockchain the end user is able to realize things that fail with any other certification. [Respondent 3].

A last significant child node concerns the disclosure of more confidential data and hence the management of privacy. In this case, attention is no longer paid to information that intrigues the consumer but rather to what data the company can load without incurring theft (plagiarism) from other competitors.

As regard the territorial identity, this issue is the subject of heated debate between those who support the enhancement of Made in Italy and those who do not entirely agree. In favour of the territoriality exaltation, the product geolocation is made visible 
through the inclusion of maps, satellite photographs and films showing the origin of the bottle of wine in the code on the label.

[...]Certainly it is a very direct system that shows the consumer the related cultivation and this is very important because from there we can even get the satellite photo. [...]. Compared to what already exists about the territorial identity and the Made in Italy, the blockchain solution provides great results. [Respondent 8].

\subsection{Group 4: Training and Dissemination}

The collaboration discussed in the previous sub-paragraph is also influenced by the "Training" of those who contribute to the development of the supply chain activities. In this case the boundary objects between the third and the fourth group are the two micro-themes "Skills" and "Required Figures". For this reason, the discussion shifts to the need for trained and experienced figures in the use of advanced technologies. Since both the organization and the supply chain managerial mechanism remain unchanged, the skill required by the pilot companies was the ability to find accurate and precise information. No external staff were hired because consultants had been involved in the implementation of the solution. Many of the respondents felt the need to gain a better understanding of how the technology functions, a greater ability to disseminate the benefits of the blockchain applications to consumers, and the desire to create awareness among other companies in the wine and agro-food industry.

It is one of those innovative and pioneering technologies. Let me explain... it is a technology that is widely known and used, but in the application of supply chain it is certainly pioneering. [...] So maybe in 10 years time all the products all over the world will come out in blockchain because it will be what the market wants. [Respondent 3].

According to the interviewees, large-scale retailers or government institutions (e.g. Ministry of Agriculture) would undoubtedly promote this new scenario.

\subsection{Comparison of Wineries Versus Developers}

The issues discussed with the pilot companies were undertaken with the two developer companies (Table 3).

This in-depth analysis aims to allow the technology experts to clarify some aspects neglected in the interviews with the pilot companies. It was decided to compare the two perspectives only on the issues that were defined as boundary objects, or the

Table 3 "Out-of-the sample respondents" features (authors' elaboration)

\begin{tabular}{l|l|l}
\hline Respondent & Position & Project owner \\
\hline Respondent A & Business developer & Ambrosus \\
\hline Respondent B & Business analyst & Food chain \\
\hline
\end{tabular}


link between the four groups of categories already identified and analysed, namely "Transparency", "Management of the supply chain" and "Training".

Companies see the principal utility of blockchain in transparency: it is perceived as a guarantee for the consumer, the company itself and the territory. Developers, however, consider it to be secondary compared to the management benefits. Contrary to what developers expected, companies did not significantly change any process within their wine supply chain management. For both companies and developers, blockchain is seen as a constant traceability guarantee, thanks to the use of a management platform with a friendly-user interface.

[...] There is a conflict of interest between what the blockchain entails and what the activity is because the blockchain $[\ldots]$ provides more visibility than daily activities. For example, information about the logistics process or company policy can be provided, even if not everyone is obviously willing to give this kind of data to their customers. So if an operator (let's say one in logistic) who tends to have a $1-2 \%$ error by not respecting the declared SLAs cannot deal with the blockchain because with the blockchain it becomes very difficult to manipulate this information. [Respondent A].

Training is the only contact point between the two perspectives. Both wineries and developers do not consider it necessary to employ any new IT-oriented staff because the technology is developed by third parties and company workers will have time to learn. Instead, more information on data security and privacy issues should be disclosed.

\section{Discussion}

The authors have identified which positive factors and limitations experts perceive during the experimentation of blockchain in the wine industry. According to the results of the analysis the two hypotheses formulated above were not proven. A gap was found between what was presented in the scientific literature and the actual state of the art in the context examined. This was further supported by the discordant points of view that emerged during the comparison between companies and developers. The pilot companies seem to have taken into account only the communication aspects linked to marketing and transparency. Empowering the final consumer or providing more in-depth information to gain entrance to new markets is their main goal.

Developers, while confirming the importance of the previous point of view, are more conscious that the real change is in the simplification and efficiency of the business processes that are the basis of the correct development of the supply chain and the improved awareness of the actors involved.

The only contact point seems to be training, which is perceived as the need for greater dissemination and consciousness of what the blockchain is and how it should be implemented. However, some considerations need to be made in favour of the analysis of the pilot companies. Since the projects were carried out on only a small group of wine producers and under a limited period of time, it is too early to observe concrete changes in all the related business processes and, consequently, a tangible 
evolution in the supply chain function. We do expect that the long-term adoption and spread of the blockchain technology will have a stronger impact in the whole sector.

From the point of view of the consumer no result was found but this may be as a consequence of the time factor required to launch blockchain certified products on the market and understand what the real impact on consumers is. The answers given by the pilot companies to the questions on the topic were based on expectations, hopes and forecasts to be verified, once again, only in the long term. The most evident benefit was the commitment at the organisational and supply chain level to a careful search for the information to be recorded in blockchain. The possibility of tracing the supply chain in detail has also given space to those players such as winemakers whose work seems to stop once the harvest is over.

The perception of greater transparency for consumer protection has also increased. The recording of information validated by a certification body in the first instance has imparted more protection to companies encouraged by the fact that they do not input data directly into the blockchain. A third body does it and usually is accredited and recognized at national and international level (DNV GL in the case of MyStory and Ernst and Young for Wine Blockchain EY). This reduces the autonomous nature of blockchain technology because it is private, and the companies do not have full control of the published data, resulting in the disappearance of two of the main features of the technology, namely decentralization and disintermediation.

The exploratory analysis carried out has some research limitations. Despite a group of sixteen companies participating in the three projects, only seven of them made themselves available for interviews. The small sample on which the qualitative analysis was carried out precludes the possibility of extending the results of the research beyond the boundaries of the sample itself. Finally, the main limitation was the lack of opportunity to also listen to the point of view of the companies that provided the technology in the wine sector, of the EY consulting firm and DNV GL certification body. Being aware of the perspectives of the three organizations, for example, would have provided a deeper understanding of the reasons behind the implementation of a private blockchain solution and a better analysis of the issues of data recording through appropriate platforms created ad hoc. Listening and including the point of view of all the actors involved would have opened up new research paths and other aspects of the subject matter.

\section{References}

1. Brody, P. (2017). How blockchain is revolutionizing supply chain management. D!gitalist Magazine. http://www.digitalistmag.com/tag/Blockchain-and-supplychain. 28/11/2018 viewed.

2. Cangelosi, G. M. (2019). In vino veritas? La Blockchain nella filiera vitivinicola italiana (Master research thesis). University of Trento, Trento, Italy.

3. Morabito, V. (2017). Business innovation through blockchain: The B. perspective. Milano: Springer. http://Blockchainstudies.org/files/Morabito.pdf. 23/2/2019 viewed. 
4. Wright, A., \& De Filippi, P. (2015). Decentralized blockchain technology and the rise of lex cryptographia.

5. Benos, E., Garratt, R., \& Gurrola-Perez, P. (2017). The economics of distributed ledger technology for securities settlement. https://www.bankofengland.co.uk/-/media/boe/files/ working-paper/2017/the129economics-of-distributed-ledger-technology-for-securities-settle ment.pdf. 23/2/2019 viewed.

6. Bellini, M. (2017). Blockchain per la smart agrifood: EY presenta Wine Blockchain con EZ $L A B$ a difesa del Vino Made in Italy. Blockchain4innovation. https://www.blockchain4inno vation.it/mercati/agrifood/blockchain-la-smartagrifood-ey-presenta-wine-blockchain-difesadel-vino-made-italy/. 18/11/ 2018 viewed.

7. Zheng, Z., Shaoan, X., Hongning, D., Xiangping, C., \& Huaimin, W. (2017). An overview of blockchain technology: Architecture, consensus, and future trends. In IEEE 6th International Congress on Big Data, (pp. 557-564). IEEE, Honolulu, HI, USA.

8. Abeyratne, S. A., \& Monfared, R. (2016). Blockchain ready manufacturing supply chain using distributed ledger. International Journal of Research in Engineering and Technology, 5(9), $1-10$.

9. Francisco, K., \& Swanson, D. (2018). The supply chain has no clothes: Technology adoption of blockchain for supply chain transparency. Logistics, 2(1), 1-13.

10. Christidis, K., \& Devetsikiotis, M. (2016). Blockchains and smart contracts for the internet of things. IEEE Access, 4, 2292-2303.

11. Zyskind, G., \& Nathan, O. (2015). Decentralizing privacy: Using blockchain to protect personal data. In 2015 IEEE Security and Privacy Workshops, (pp. 180-184). IEEE, The Fairmont, San Jose, CA.

12. Lin, I.-C., \& Liao, T.-C. (2017). A survey of blockchain security issues and challenges. $I J$ Network Security, 19(5), 653-659.

13. Reyna, A., Martín, C., Chen, J., Soler, E., \& Díaz, M. (2018). On blockchain and its integration with IoT. Challenges and opportunities. Future Generation Computer Systems, 88, 173-190.

14. Rodrigo, M. N. N., Perera, S., Senaratne, S., \& Jin, X. (2018). Blockchain for construction supply chains: A literature synthesis. In Proceedings of the 11 th International Cost Engineering Council (ICEC) World Congress \& the 22nd Annual Pacific Association of Quantity Surveyors Conference, (pp. 18-20). Sydney, Australia.

15. Vukolić, M. (2017, April). Rethinking permissioned blockchains. In Proceedings of the ACM Workshop on Blockchain, Cryptocurrencies and Contracts, (pp. 3-7). ACM.

16. Beck, R., \& Müller-Bloch, C. (2017). Blockchain as radical innovation: a framework for engaging with distributed ledgers as incumbent organization. In Proceedings of the 50th Hawaii International Conference on System Sciences (pp. 5390-5399). Hilton Waikoloa Village, Hawaii.

17. Faioli, M., Petrilli, E., \& Faioli, D. (2016). Blockchain, contratti e lavoro. La ri-rivoluzione del digitale nel mondo produttivo e nella PA. Economia \& lavoro, 50(2), 139-158.

18. Atzori, M. (2015). Tecnologia Blockchain E Governance Decentralizzata: Lo Stato È Ancora Necessario? (Blockchain technology and decentralized governance: Is the state still necessary?). Blockchain technology and decentralized governance: Is the state still necessary.

19. EUIPO. (2016). Il costo economico della violazione dei diritti di proprietà intellettuale nel settore degli alcolici e dei vini. Alicante, Spagna. https://euipo.europa.eu/tunnel-web/secure/ webdav/guest/document_library/observatory/resources/research-and-studies/ip_infringem ent/study8/wines_and_spirits_it.pdf. 12/5/2019 viewed.

20. Cisco. (2017). Ricerca Cisco_Digital transformation Institute: il settore agroalimentare Italiano deve prendere il treno della digitalizzazione adesso. Cisco. Disponibile da https://www. cisco.com/c/it_it/about/news/2017-archive/20170504.html. 20/2/2019 viewed.

21. Biswas, K., Muthukkumarasamy, V., \& Lum, W. (2017). Blockchain based wine supply chain traceability system. In Future Technologies Conference, (pp. 1-7). Vancouver, BC, Canada. 